\title{
Analysis of Designs of Distribution Systems of Grain Pneumatic Seeders
}

\author{
Azamat E Bogus ${ }^{1,}$, Vladislav Stanin ${ }^{1}$, and Alina Vyshebabina $^{1}$ \\ ${ }^{1}$ Chair "Processes and machines in agribusiness" of the faculty of mechanization of Kuban State \\ Agrarian University named after I.T.Trubilin, 350044, Krasnodar, Russia \\ ${ }^{2}$ Kuban State Agrarian University named after I.T.Trubilin, 350044, Krasnodar, Russia
}

\begin{abstract}
The design of distribution systems of modern pneumatic grain seeders is considered. Classifications of central metering systems and distribution systems have been compiled. The advantages and disadvantages of distribution systems of different designs are described.
\end{abstract}

\section{Relevance of research}

Increasing the yield of winter wheat is a systemic task, which is carried out through the development of new high-yielding varieties, the development of new cultivation technologies, the use of fertilizers, etc. Among these factors, an important place is occupied by the development of modern sowing machines that can produce crops at a higher quality level. With constant acreage, an increase in grain production is possible by increasing the yield and reducing its losses during sowing and harvesting. The most promising are pneumatic grain seeders, which, due to a single common hopper and a pneumatic distribution system, can reduce labor costs by up to $30 \%$ and increase the productivity of the sowing unit by up to $25 \%$.

However, despite all the advantages, pneumatic grain seeders do not always provide a high-quality distribution of seed material through seed lines.

\section{Designs of distribution systems of grain pneumatic seeders}

The systems of central dosing of grain pneumatic seeders consist of a common hopper with a common seeding apparatus, pneumatic conveying lines with a source of excess air pressure and a system that distributes seeds $[4,5]$. The classification of central dosing systems is shown in Figure $1[3,8,9]$.

\footnotetext{
* Corresponding author: azamat089@gmail.com
} 


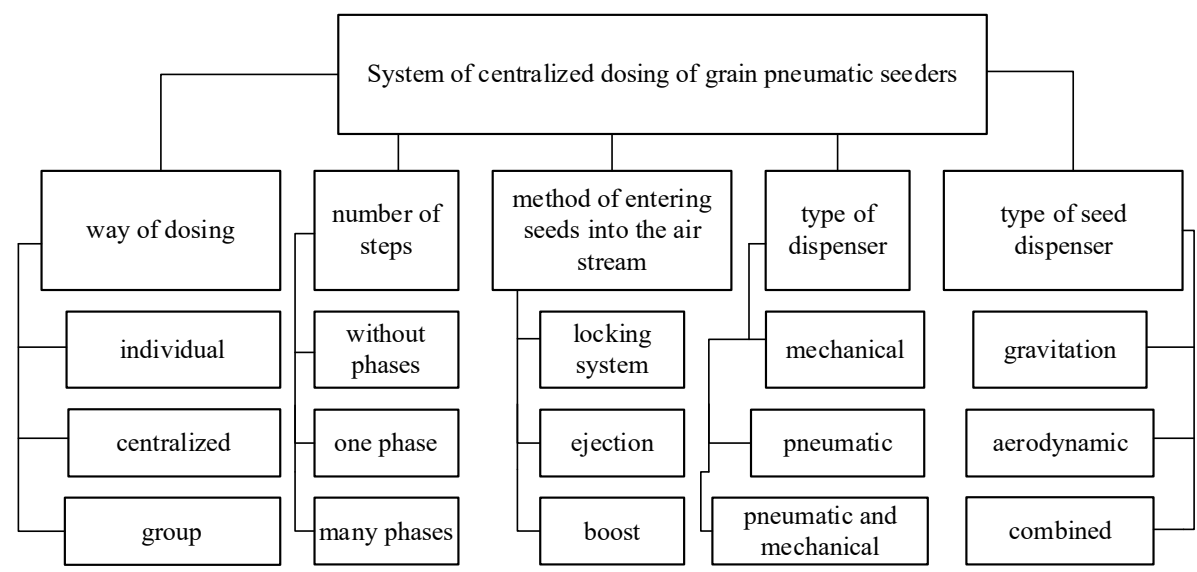

Fig. 1. Classification of central grain dosing systems for pneumatic seeders.

The distribution devices of pneumatic grain seeders have a significant impact on the quality of seed distribution between seed lines. The design of the distribution systems determines the transverse and longitudinal uniformity of seeding and the degree of injury to seeds. Manufacturers of sowing equipment are aimed at improving the uniformity of seed distribution through seed lines.

Based on the analysis of patents and literature sources $[1,6,7,11,12]$ there are two main types of distribution devices of pneumatic grain seeders: vertical (Figure 2 a) and horizontal (Figure 2 b).

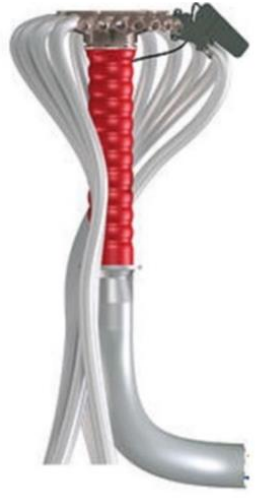

a

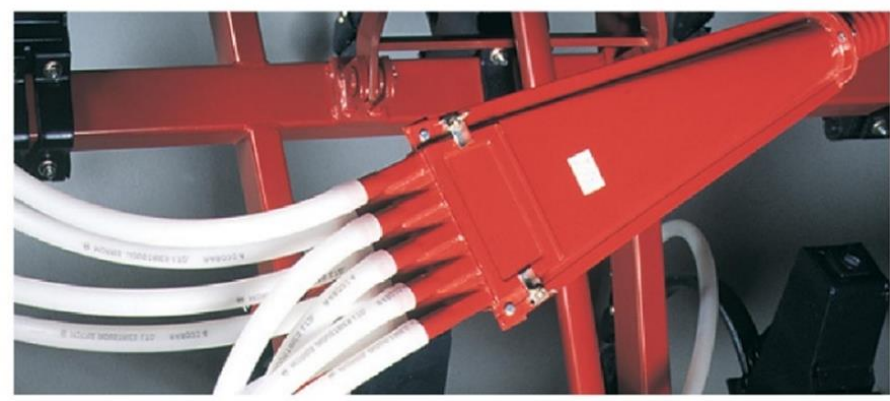

b

$\mathrm{a}$ - vertical; b - horizontal

Fig. 2. Types of distribution devices.

The vertical distribution system consists of a pneumatic pipe that rotates at right angles and a head that is a body of rotation with radial discharge pipes and a reflective surface inside. Vertical seed dispensers usually differ in the shape of the reflecting surface of the feed column. There are designs of vertical seed dispensers in which the grain-air mixture moves up the falling column, and there are those in which it moves down. The various schemes of seed distributors are shown in Figure 3. Vertical distribution devices are simple and reliable, but they have a high energy consumption, which is associated with the need to raise the grain-air mixture to the height of the reflective surface [10]. 


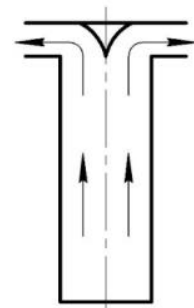

a

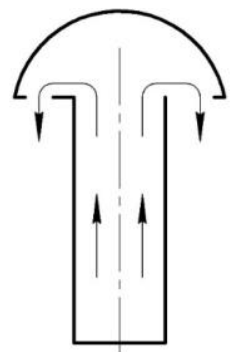

$\mathrm{b}$

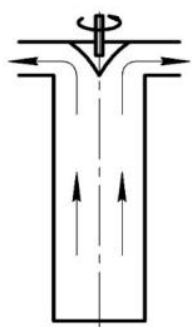

c

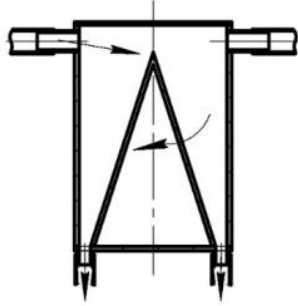

d

$a, b$-with fixed reflective surfaces; $\mathrm{c}$ - with a rotating reflective surface; $\mathrm{d}$ - centrifugal type

Fig. 3. Scheme of vertical seed dispensers

The designs of seed dispensers with fixed reflecting surfaces (Figure $3 a, b$ ) are widely used due to their simplicity and reliability. The shape of the reflective surface is very diverse: flat, pyramidal, spherical, conical, etc. The use of dispensers of this type makes it possible to obtain uniformity in the seed distribution between the seed lines, provided that turbulators are used within $90 \%$ [2].

Active distribution systems (Figure $3 b$ ) have a reflecting rotating or vibrating surface with blades and senders in their design, they can be reactive and driven. Distribution devices of this type are complex in their design and technological adjustments, their reliability is lower, according to researches $[4,5]$ do not significantly increase the uniformity of the seed distribution over the feeding area.

A significant influence on the seed distribution is equally exerted by the uniformity of the seed distribution in the cross-section of the supply pneumatic pipe. For the symmetrical feed of the grain-air mixture, various turbulators and seed senders are used [11].

The classification scheme of distribution devices of pneumatic grain seeders is shown in the Figure $4[3,7,8,9]$.

Horizontal dispensers of the unit consist of a horizontal pneumatic pipeline connected to an expanding bell, in which the discharge pipes are located. Horizontal seed dispensers have a good uniformity of seed distribution between seed lines, have a low energy consumption, but do not work well on slopes and are not able to serve a large number of coulters. Despite the advantages described, horizontal distribution systems are not widely used on pneumatic grain seeders.

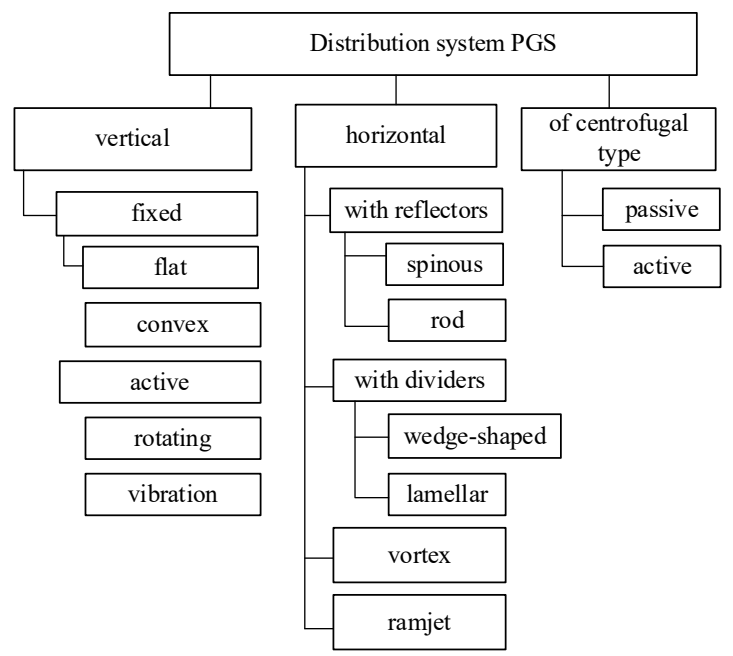

Fig. 4. Classification of distribution devices of pneumatic grain seeders. 


\section{Conclusions}

The analysis of the designs of pneumatic grain seeders showed that most of the produced sowing machines use vertical distribution devices with fixed reflective surfaces, the main disadvantage of which is the high unevenness of the seed distribution along the seed lines.

\section{References}

1. Yu. Popov, D.K. Muratov, Study of the sealing elements impact on air flow distribution in a seed vessel of seeding mechanism, MATEC Web Conferences, Vol. 224, 05055(2018). DOI: https: //doi.org /10.1051 / matecconf / 201822405015.

2. Akhalaya B. Kh. A laboratory study of the pneumatic sowing device for dotted and combined crops // AMA, Agricultural Mechanization in Asia, Africa and Latin America.-2019. - Vol. 50. -N 1.- P. 57-59.

3. Astakhov V.S. Analysis of pneumatic centralized sowing systems // Tractors and agricultural machines. - 1997. №. 10. - pp. 33-34.

4. Bogus A. Analytical study of uneven distribution of seeds by a centrifugal distributor/ A. Bogus // E3S Web of Conferences: International Conference on Modern Trends in Manufacturing Technologies and Equipment - 2020.

5. Bogus A. Investigation of the kinematics of seed movement in the centrifugal distributor of a pneumatic seeder / A. Bogus // E3S Web of Conferences: International Conference on Modern Trends in Manufacturing Technologies and Equipment - 2020. https://doi.org/10.1051/e3sconf/202019301017.

6. Bogus A. Substantiation of the technological scheme of pneumatic grain seeder of subsurface dense sowing / Bogus A. E., Kuzmenko A. D. // E3S Web of Conferences. 2019. - P. 00040.

7. Klenin N.I. Agricultural machines : manual / N. I. Klenin, S. N. Kiselev, A. G. Levshin (M.: KolosS, 2008).

8. Kryuchin N.P. Development of a pneumatic seeder for sowing herbs-phytomeliorants // In thecollection: Tehnogennaja i prirodnaja bezopasnost' materialy IV Vserossijskoj nauchno-prakticheskoj konferencii [Technogenic and natural safety materials of the IV All-Russian Scientific and Practical Conference]. Saratov State Agrarian University named after N.I. Vavilov Publ. 2017. pp. 253-257.

9. N. P. Kryuchin, O. N. Serobaba, D. N. Kotov, A. N. Kryuchin Pat. №181167, Russian Federation, IPC A01C 7/00. Screw sowing apparatus. - №2018106609, declared 02/21/2018; publ. 07/05/2018 Bull. №19.

10. Kulen A. Modern agricultural machinery [Text] / A. Kulen, Kh.Kuipers. Translation from A.E.Gabrielyan; under edition and with introduction Yu. A. Smirnov, M.: Agropromizdat, 1986.

11. N. P. Kryuchin, O. N. Serobaba, D. N. Kotov, A. N. Kryuchin Pat. №181167, Russian Federation, IPC A01C 7/00. Screw sowing apparatus. - №2018106609, declared 02/21/2018; publ. 07/05/2018 Bull. №19.

12. Yu. A. Saveliyev, N. P. Kryuchin, D. N. Kotov, A. N. Kryuchin. Pat No. 133677, Russian Federation, IPC A01C 7/00. Sowing apparatus. - № 2013121148/13; declared 05/07/2013; publ. 10/27/2013, Bull. №30. 